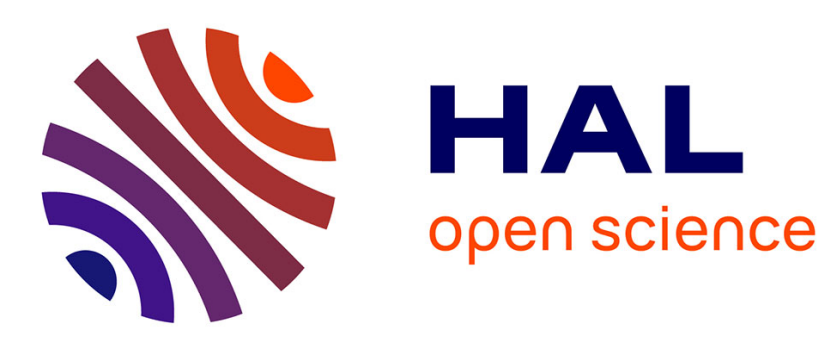

\title{
Compact Rectenna for Space Application
}

\author{
Alexandru Takacs, Hervé Aubert, Samuel Charlot, S Fredon, L Despoisse
}

\section{To cite this version:}

Alexandru Takacs, Hervé Aubert, Samuel Charlot, S Fredon, L Despoisse. Compact Rectenna for Space Application. International Microwave Symposium, Jun 2014, Tampa, United States. 4p. hal01875623

\section{HAL Id: hal-01875623 \\ https://hal.laas.fr/hal-01875623}

Submitted on 17 Sep 2018

HAL is a multi-disciplinary open access archive for the deposit and dissemination of scientific research documents, whether they are published or not. The documents may come from teaching and research institutions in France or abroad, or from public or private research centers.
L'archive ouverte pluridisciplinaire HAL, est destinée au dépôt et à la diffusion de documents scientifiques de niveau recherche, publiés ou non, émanant des établissements d'enseignement et de recherche français ou étrangers, des laboratoires publics ou privés. 


\title{
Compact Rectenna for Space Application
}

\author{
A. Takacs ${ }^{1,2}$, H. Aubert ${ }^{1,3}$, S. Charlot ${ }^{1}$, S. Fredon ${ }^{4}$, L. Despoisse, \\ ${ }^{1}$ CNRS, LAAS, 7 avenue du colonel Roche, F-31400 Toulouse, France \\ ${ }^{2}$ Univ. de Toulouse, UPS, LAAS, F-31400, Toulouse, France \\ ${ }^{3}$ Univ. de Toulouse, INP, LAAS, F-31400, Toulouse, France \\ ${ }^{4}$ CNES (French Space Agency), F-31400, Toulouse, France \\ ${ }^{5}$ Thales Alenia Space, F-06150, Cannes, France
}

\begin{abstract}
This paper addresses an ultra-compact $\left(2.8 \mathrm{~cm}^{2}\right)$ and wide bandwidth rectenna operating in the extended $\mathrm{Ku}$ band. Experimental results demonstrate that the proposed rectenna can harvest a DC power ranging from $0.125 \mathrm{~mW}$ to 1.43 $\mathrm{mW}$ for frequencies between $14.5 \mathrm{GHz}$ to $19.5 \mathrm{GHz}$ and for resistive loads between $250 \Omega$ and $4 \mathrm{k} \Omega$. A maximum conversion efficiency of $55.3 \%$ is obtained at $16.05 \mathrm{GHz}$ for an incident power density around of $1.26 \mathrm{~mW} / \mathrm{cm}^{2}$. It is the first time, to the authors' knowledge, that such high harvesting performances are obtained using an ultra-compact Ku-band rectenna.

Index Terms- Rectenna, energy harvesting, satellite application.
\end{abstract}

\section{INTRODUCTION}

Nowadays high bit rate, reliable and long-life satellite-based broadcasting links are intensively used for key applications including (but not limited to) mobile communication, television and Internet. In order to provide such broadcasting links high-gain microwave operating in $\mathrm{C}, \mathrm{X}, \mathrm{Ku}, \mathrm{K}$ or $\mathrm{Ka}$ band and located on panels positioned on the external surface of the satellite antenna are used. Health monitoring of these panels is a key issue involving the use of sensors, e.g., for thermal or for mechanical/structural monitoring. Deploying such sensors in small wireless networks to cover the targeted surface seems to be a very promising technical solution by saving the cost of deploying long wires in harsh environments [1]. Because the battery are forbidden for such applications energy harvesting techniques [2] should be a possible solution for DC powering the sensors and transceivers for wireless sensor networks [1]. In some areas located on antenna panels of broadcasting satellites, the electric field available from the spill-over loss of microwave antennas can reach the maximum levels (effective values) of $106 \mathrm{~V} / \mathrm{m}$ in $\mathrm{Ku}$-band and $127 \mathrm{~V} / \mathrm{m}$ in K-band [1]. We present here the design and measurement of an ultra-compact rectenna for the $\mathrm{Ku}$-band electromagnetic energy harvesting. A minimal and ultra-compact topology with a wide band behavior is reported here for the first time.

\section{ULTRA-COMPACT RECTENNA: TOPOLOGY AND DESIGN}

Rectennas are intensively used for wireless power transfer or electromagnetic energy harvesting applications. Several designs and topologies have been proposed for various applications covering GSM/UMTS, GPS, C and X bands. The frequency spectrum covering the $\mathrm{Ku}$ band and above has been addressed in the past mainly for wireless power transfer application [3],[4]. Recall that, as defined by Radio Society of Great Britain, the $\mathrm{Ku}$ band covers frequencies ranging from $12 \mathrm{GHz}$ to $18 \mathrm{GHz}$. Energy harvesting of the ambient electromagnetic power at such high frequencies was not yet deeply investigated because of the lack of powerful environmental electromagnetic sources for terrestrial applications. Recently several research works have been reported on the rectenna design for electromagnetic energy harvesting at frequencies covering mainly the $24 \mathrm{GHz}$ (ISM) band [5],[6]. Fig. 1 shows a photo of the manufactured rectenna for $\mathrm{Ku}$-band application and the associated FEKO simulation model. The rectenna is composed by a dual dipolelike antenna (DDLA) directly connected to a Schottky diode. A similar topology, operating at $2.45 \mathrm{GHz}$, was proposed in [7]. A zero-bias GaAs beam lead planar doped diode (Aeroflex/Metelics MZBD-9161) was selected for this design. The main selection criteria were the thermal and RF behavior of this diode regarding the targeted space application. A capacitance $(1.5 \mathrm{pF})$ connected in parallel with the diode is used to short any undesirable high frequency and acts as a low pass filter.

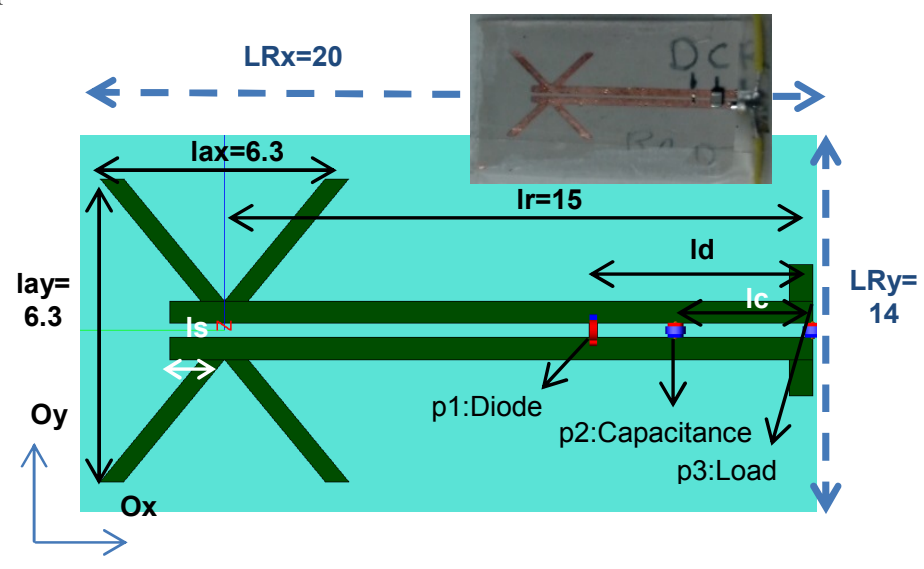

Fig. 1. Top view (not to scale) of the simulation model (Feko) of the fabricated rectenna. The inset shows a photo of the prototype. 
The rectenna was fabricated on Rogers 6002 substrate (relative permittivity: 2.94, loss tangent: 0.0012 , thickness: $508 \mu \mathrm{m}$ ). The dimensions (in $\mathrm{mm}$ ) of the rectenna are shown in Fig. 1. The coplanar stripline presents strips width of $w=0.8$ $\mathrm{mm}$ and a gap size of $\mathrm{g}=0.4 \mathrm{~mm}$. A metallic plate acting as a reflector was positioned at $2 \mathrm{~cm}$ below the DDLA in order to increase the antenna gain in the operating frequency band.

The antenna is composed by two crossed dipoles excited by the coplanar stripline. No matching circuit is used between antenna and the diode/rectifier input. The matching between antenna and the diode/rectifier as well as the backscattering suppression of the higher order harmonics of the operating frequency were achieved by properly controlling the input impedance of the antenna and the diode/capacitance mounting position. The proposed design methodology combines fullwave electromagnetic simulation and non-linear circuit simulation. The main goal is to simultaneously achieve a high gain for the DDLA with an acceptable matching between this antenna and the rectifier in a large bandwidth and for various load impedance and incident RF power. This was done in order to maximize the overall conversion efficiency of the rectenna. The design procedure consists of the following steps:

(i) the DDLA was first designed, simulated and optimized using FEKO software for operation in the desired frequency band. The diode was replaced by a voltage port while the capacitance $(1.5 \mathrm{pF})$ and the load (e.g. $500 \Omega)$ were modeled as port loads. The antenna radiation pattern and the distribution of the electric currents on the metallic strips were analyzed in order to insure the proper radiation mechanism and to maximize the gain on the vertical $\mathrm{Oz}$ axis (that is, in the direction perpendicular to the rectenna plane);

(ii) the input impedance (Zin_a) as well as the gain along the Oz-axis (theta $=0^{\circ}$; phi $=0^{\circ}$ ) of the DDLA (simulation model shown in Fig. 1) was computed in the targeted frequency band as a function of the diode/capacitance mounting position;

(iii) non-linear (harmonic balance) simulation was performed by using the AWR model shown in Fig. 2 for the so-called 'rectifier' (composed by the diode, the capacitance and the load). The coplanar stripline sections supporting the rectifier were modeled as a sub-circuit at the electromagnetic level because of the lack of an appropriate transmission line model in AWR. A generic non-physical diode model available in AWR was customized with the MZBD-9161 diode parameters. The input impedance (Zin_r) of the rectifier was determined as a function of the diode/capacitance mounting position;

(iv) the diode and capacitance position was tuned in order to assure the matching condition, that is Zin $\_a=Z i n \_r{ }^{*}$ where the asterisk denotes the complex conjugated.

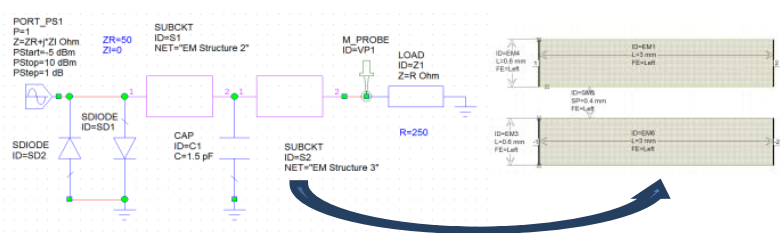

Fig. 1. AWR model used for the rectifier simulation.

\section{SiMULATION AND EXPERIMENTAL RESUlTS}

The simulated impedance (Zin_a) viewed at port $p 1$ (see Fig. 1) with the port $p 2$ loaded by $\mathrm{C}=1.5 \mathrm{pF}$ and the port $p 3$ loaded by $\mathrm{RL}=250 \Omega$ was calculated from FEKO simulation software (method of moments) based on the planar (infinite) multilayered substrate approach. Fig. 3 displays Zin_a for $\mathrm{ld}=5.5 \mathrm{~mm}$ and $\mathrm{lc}=3.5 \mathrm{~mm}$. The input impedance of the rectifier Zin_r computed from AWR simulation is shown in Fig. 4 for a $\mathrm{RF}$ input power at rectifier input port ranging from $-10 \mathrm{dBm}$ to $15 \mathrm{dBm}$. The real part of this impedance decreases as the frequency or RF input power increases. The imaginary part is always negative and increases as the frequency or RF input power increases.

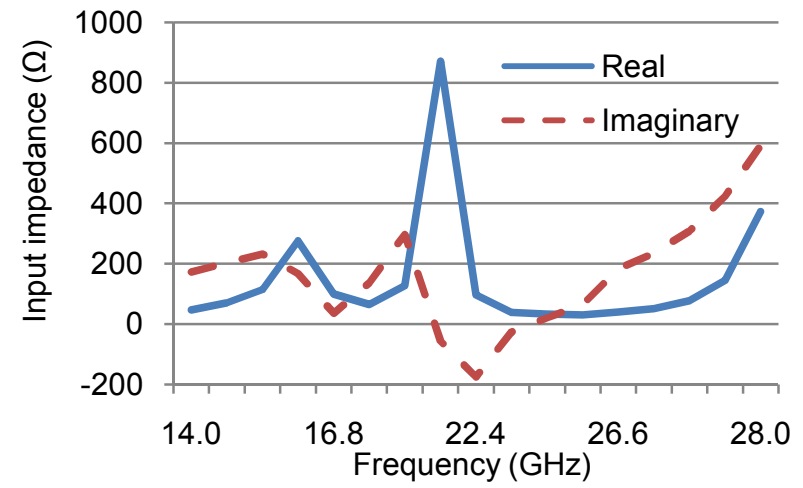

Fig. 3. Simulated (FEKO) impedance Zin a at port $p 1$ (see Fig. 1) when the port $p 2$ is loaded by $\mathrm{C}=1.5 \mathrm{pF}$ and the port $p 3$ is loaded by $\mathrm{RL}=250 \Omega(\mathrm{ld}=5.5 \mathrm{~mm}$ and $1 \mathrm{c}=3.5 \mathrm{~mm})$

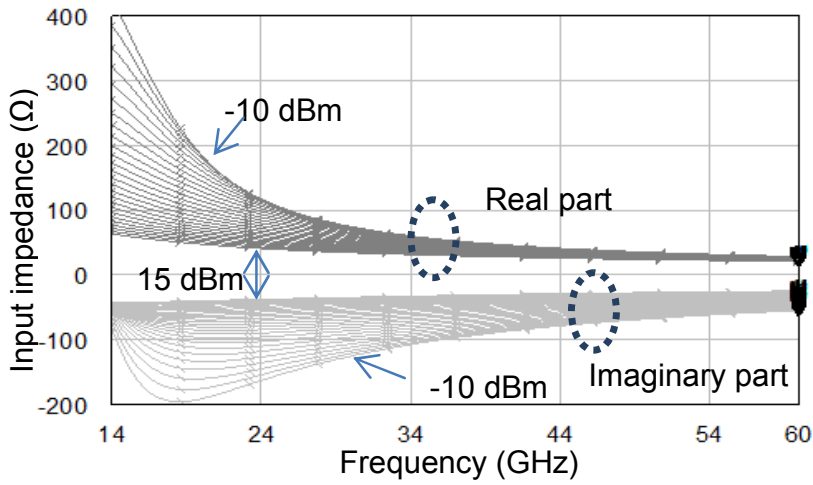

Fig. 4. Simulated (AWR) input impedance Zin_r of the rectifier when the port $p 2$ is loaded by $\mathrm{C}=1.5 \mathrm{pF}$ and the port $p 3$ is loaded by $\mathrm{RL}=250 \Omega(\mathrm{ld}=5.5 \mathrm{~mm}$ and $\mathrm{lc}=3.5 \mathrm{~mm}$. 
Fig. 5 reports the simulated gain (FEKO) in $\mathrm{dBi}$ along the Ozaxis (theta $=0^{\circ} ; \mathrm{phi}=0^{\circ}$ ) and the measured gain of the horn antenna (VT220HA20-SK from Vector Telecom) used for the experimental setup described in the next section. As shown in this figure DDLA has at least $8 \mathrm{dBi}$ of gain along of Oz-axis for frequencies between $14 \mathrm{GHz}$ and $20 \mathrm{GHz}$.

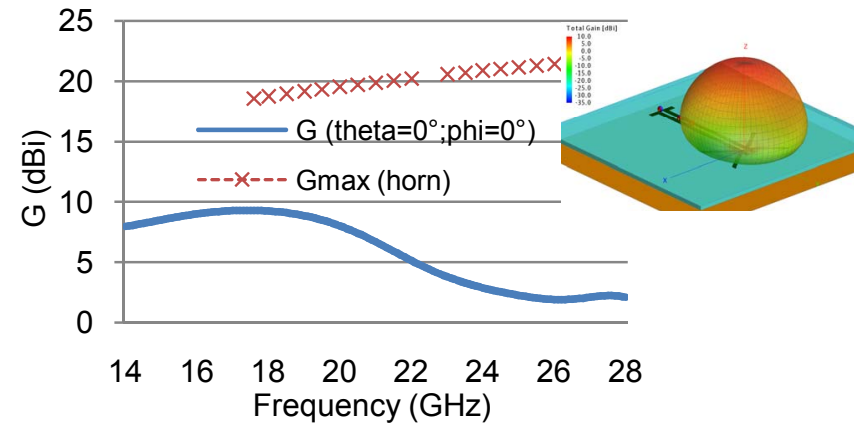

Fig. 5. Simulated (FEKO) gain along Oz-axis of the DDLA and the measured maximum gain of horn antenna used for measurement. The inset shows the simulated 3D radiation pattern of the rectenna.

In order to characterize the performances of the proposed rectenna an experimental setup (inset of Fig. 6) was used. A continuous wave microwave signal (RF power: $24 \mathrm{dBm}$ ) generated by the Anritsu MG3694B was injected at the input port of a horn antenna (VT220HA20-SK from Vector Telecom) used for illuminating the rectenna under test with a linearly polarized E-field. The measured loss due to the coaxial cable and connectors between antenna and the signal generator was $2 \mathrm{~dB}$ in the $\mathrm{Ku}$ band. An automatic acquisition routine was implemented in Labview software from National Instruments in order to facilitate the acquisition process. A variable resistor RL was used for loading the rectenna. Fig. 6 shows the DC power injected in the load impedance as a function of RL at $16.05 \mathrm{GHz}$.

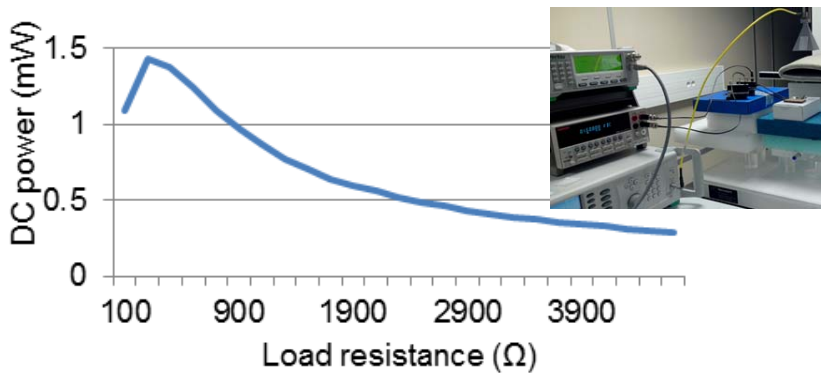

Fig. 6. Measured DC power obtained from a RF power of $24 \mathrm{dBm}$ delivered by the signal generator as a function of the load resistance $\mathrm{RL}$ at $16.05 \mathrm{GHz}$.

Fig. 7 represents the DC voltage measured for three resistive loads $(250 \Omega, 1 \mathrm{k} \Omega$ and $4 \mathrm{k} \Omega$ ) as a function of frequency. The DC voltage increases as the load impedance increases and is higher than $0.2 \mathrm{~V}$ for any resistive load impedance between $250 \Omega$ and $4 \mathrm{k} \Omega$ in a wide bandwidth, i.e., for frequencies ranging from $14 \mathrm{GHz}$ to $20 \mathrm{GHz}$. The DC power delivered to the load RL is shown in Fig. 8. We note that the harvested DC power increases as the load resistance decreases. A maximum value of $1.43 \mathrm{~mW}$ is obtained $(\mathrm{RL}=250 \Omega)$ at $16.05 \mathrm{GHz}$. For any load impedance between $0.25 \mathrm{k} \Omega$ and $4 \mathrm{k} \Omega$ the harvested DC power is found to be higher than $0.125 \mathrm{~mW}$ in a wide frequency band, i.e., for frequencies ranging from $14.5 \mathrm{GHz}$ to $19.5 \mathrm{GHz}$. It is the first time, to the authors' knowledge, that such wide band harvesting performances are obtained using an ultra-compact Ku-band rectenna.

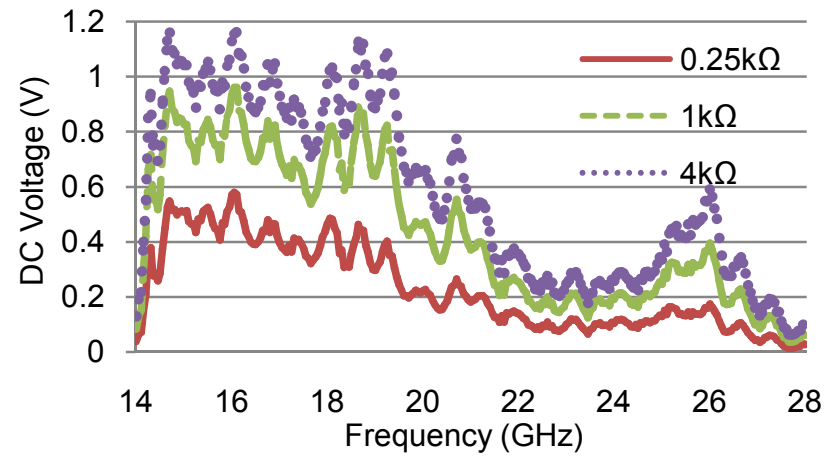

Fig. 7. Measured DC voltage at the input ports of the load impedance obtained for a RF power of $24 \mathrm{dBm}$ delivered by the signal generator and for various load impedance.

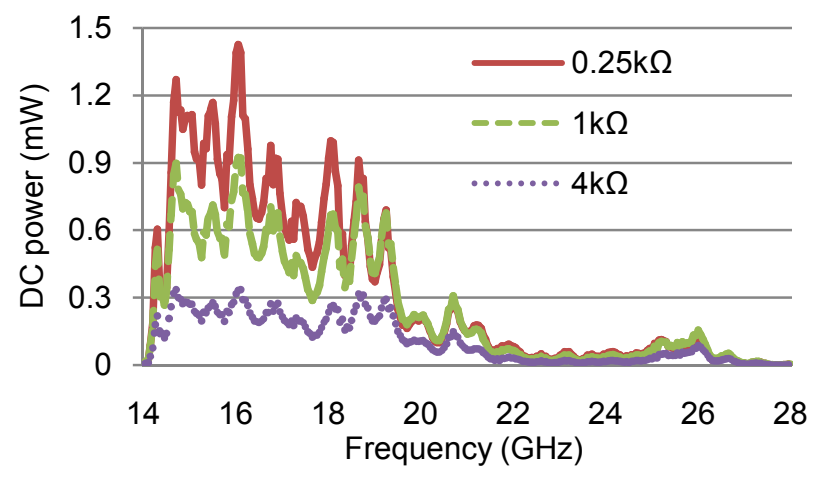

Fig. 8. Measured DC power delivered to the load obtained for a RF power of $24 \mathrm{dBm}$ provided by the signal generator and for various load impedances

The efficiency $\eta$ (in \%) of a rectenna can be computed by using the following worst-case definition [2]:

$$
\eta=\frac{P_{D C}}{S \cdot A_{G}} \cdot 100
$$

where $\mathrm{P}_{\mathrm{DC}}$ is the harvested $\mathrm{DC}$ power, $\mathrm{S}$ is the incident electromagnetic power density and $\mathrm{A}_{\mathrm{G}}$ (in $\mathrm{cm}^{2}$ ) denotes the area of the radiating surface. The power density $\left(\mu \mathrm{W} / \mathrm{cm}^{2}\right)$ : can be computed as a function of E-field effective value $\mathrm{E}$ $(\mathrm{V} / \mathrm{m})$ on the antenna surface or as a function of the RF power $P_{t}$ delivered to the transmitting horn antenna of gain $G$ and positioned at the distance $\mathrm{d}$ from the rectenna under test, as follows:

$$
S=\frac{E^{2}}{120 \cdot \pi} \cdot 100=\frac{30 \cdot P_{t} \cdot G}{d^{2} \cdot 120 \cdot \pi} \cdot 100
$$


Here $\mathrm{P}_{\mathrm{t}}=22 \mathrm{dBm}, \mathrm{G}=18 \mathrm{dBi}$ and $\mathrm{d}=25 \mathrm{~cm}$. Thus $\mathrm{E} \sim 69.28$ $\mathrm{V} / \mathrm{m}$ and $\mathrm{S} \sim 1273 \mu \mathrm{W} / \mathrm{cm}^{2}$. The area $\mathrm{A}_{\mathrm{G}}=$ LRy $\mathrm{x}$ (LRx-ld) of DDLA is $0.83 \mathrm{~cm} \times 0.63 \mathrm{~cm}=0.523 \mathrm{~cm}^{2}$. The maximum DC power $(1.43 \mathrm{~mW})$ is obtained for $\mathrm{RL}=250 \Omega$ at $\mathrm{f}=16.05 \mathrm{GHz}$ leading to a maximum efficiency of $55.3 \%$. Nevertheless at least $0.125 \mathrm{~mW}$ (efficiency $>5 \%$ ) can be obtained in a wide frequency band $(14.5 \mathrm{GHz}$ to $19.5 \mathrm{GHz})$ for load resistance $100 \Omega<\mathrm{RL}<4 \mathrm{k} \Omega$. Works are under way for improving the low conversion efficiency obtained for some frequencies close to $17 \mathrm{GHz}$ and $18 \mathrm{GHz}$. Additional results will then be presented at the conference. Conclusion

An ultra-compact $\left(2.8 \mathrm{~cm}^{2}\right)$ rectenna and the associated design methodology for extended $\mathrm{Ku}$ band application were reported. The proposed design presents a wide-band behavior $(5 \mathrm{GHz}$ ) for a large range of load resistance (from $100 \Omega$ to $4 \mathrm{k} \Omega$ ). DC powers ranging from $0.125 \mathrm{~mW}$ to $1.43 \mathrm{~mW}$ can be harvested for an incident E-field of $69 \mathrm{~V} / \mathrm{m}$ (i,e., a power density around $1.27 \mathrm{~mW} / \mathrm{cm}^{2}$ ).

\section{ACKNOWLEDGEMENT}

This work was supported by CNES French Space Agency within the framework of R\&T $\mathrm{n}^{\circ} 115052$ contracts. The electronic laboratory of University of Toulouse (Paul Sabatier) is acknowledged for PCB manufacturing.

\section{REFERENCES}

[1] This reference has been removed because it establishes a direct connection to the authors' names

[2] Z. Popovic; E.A. Falkenstein, D. Costinett, R. Zane, "Low-Power FarField Wireless Powering for Wireless Sensors", Proceedings of the IEEE, Vol. 101, No. 6, pp.1397 -1407, June 2013.

[3] T.-W. Yoo and K. Chang, "Theoretical and experimental development of 10 and $35 \mathrm{GHz}$ rectennas," IEEE Trans. Microw. Theory Techn., vol.40, no. 6, pp. 1259-1266, Jun. 1992.

[4] Y.-J. Ren, M.-Y. Li, K. Chang, "35 GHz rectifying antenna for wireless power transmission," IET Electronics Letters, vol.43, no.11, pp.602-603, May 242007.

[5] S. Ladan, and K. Wu, "High Efficiency Low-Power Microwave Rectifier for Wireless Energy Harvesting", in Proc. IMS'2013, 2013.

[6] A. Collado, A. Georgiadis, " $24 \mathrm{GHz}$ Substrate Integrated Waveguide (SIW) Rectenna for Energy Harvesting and Wireless Power Transmission, in Proc. IMS'2013, 2013.

[7] H. Sun, Y.-X. Guo, M. He, Z. Zhong, "Design of a High-Efficiency 2.45-GHz Rectenna for Low-Input-Power Energy Harvesting", IEEE Antennas Wireless Propag. Lett., Vol. 11, pp. 929-932, 2012. 